\title{
Determinants of Neural Tube Defects among Newborns in Amhara Region, Ethiopia: A Case-Control Study
}

\author{
Abay Woday Tadesse ${ }^{D},{ }^{1}$ Ayesheshim Muluneh Kassa, ${ }^{2}$ and Setognal Birara Aychiluhm (iD) \\ ${ }^{1}$ Samara University, College of Medical and Health Sciences, Department of Public Health, Samara, Afar Region, Ethiopia \\ ${ }^{2}$ Dessie College of Health Sciences, Department of Nursing, Dessie, Amhara Region, Ethiopia \\ Correspondence should be addressed to Abay Woday Tadesse; abaywoday@yahoo.com
}

Received 10 May 2020; Accepted 20 October 2020; Published 31 October 2020

Academic Editor: Somashekhar Marutirao Nimbalkar

Copyright (c) 2020 Abay Woday Tadesse et al. This is an open access article distributed under the Creative Commons Attribution License, which permits unrestricted use, distribution, and reproduction in any medium, provided the original work is properly cited.

Background. Worldwide, an estimated 300,000 neonates are born with neural tube defects (NTDs) each year. However, NTDs are underreported in Ethiopia though it causes substantial mortality, morbidity, disability, and psychological and economic cost in the country. Moreover, the factors attributed to NTDs were not addressed. Hence, this study intended to identify the determinants of neural tube defects in Amhara Region, Ethiopia. Methods. A case-control study design was conducted among 400 newborns (133 cases and 267 controls) who were born at randomly selected public hospitals. Cases were identified using the physician diagnosis of confirmed NTDs, and the two consecutive controls were selected using a simple random sampling technique. The data analysis was done using Stata 14.0. Variables with $p$ value $<0.25$ in the bivariate analysis were entered into the multivariable logistic regression model, and a corresponding 95\% confidence interval was used to identify the predictors of NTDs. Results. In this study, fifty percent (48\%) of the cases were contributed by anencephaly. After controlling the covariates, living in rural areas (AOR $=1.78: 95 \% \mathrm{CI} 1.02$, 3.11), being illiterate $(\mathrm{AOR}=1.81: 95 \% \mathrm{CI} 1.07,4.61)$, being female newborn (AOR $=1.95: 95 \% \mathrm{CI} 1.09$, 3.50), having no $\mathrm{ANC}$ follow-up $(\mathrm{AOR}=1.93$ : $95 \% \mathrm{CI} 1.17,5.04)$, and having a previous history of NTDs (AOR $=4.39: 95 \% \mathrm{CI} 2.42,7.96)$ were the risk factors for NTDs. However, being supplemented with folic acid or multivitamins before or during pregnancy $(\mathrm{AOR}=0.37$ : 95\% CI 0.21, 0.65), never having taken any substance during pregnancy (AOR $=0.42: 95 \%$ CI $0.21,0.88$ ), and being free from medical illnesses during pregnancy ( $\mathrm{AOR}=0.27$ : $95 \% \mathrm{CI} 0.11,0.69)$ were the protective factors of NTDs. Conclusion. The study revealed different factors associated with NTDs among newborns in the region. Therefore, comprehensive preventive strategies focused on identified risk factors are needed at regional and national levels.

\section{Introduction}

Birth defects can be defined as structural or functional abnormalities, including metabolic disorders, which are present from birth [1]. Globally, An estimated 303,000 newborns die in the first month of life every year due to congenital anomalies [2]. Neural tube defects (NTDs) are major birth defects of the brain and spine that occur early in pregnancy-related to improper closure of the embryonic neural tube $[3,4]$. Neural tube defects (NTDs) are the second most common birth defect following congenital heart anomalies [1, 2, 5], and the commonest types of NTDs are spinal bifida, encephalocele, and anencephaly [3, 6, 7]. Globally, an estimated 300,000 neonates are born with neural tube defects each year [8], and 94\% of severe congenital anomalies occur in low- and middleincome countries [2]. In addition, approximately 300,000 to 400,000 babies are born each year with NTDs that result in more than 88,000 deaths and 8.6 million DALYs [9-11]. However, data on NTDs are limited in lower-income countries, and a systematic review showed that many WHO member states $(120 / 194)$ did not have any data on NTDs [1, 12]. Furthermore, the prevalence of NTD in Ethiopia varies from region to region, and its magnitude ranges between $0.61 \%$ and $40.3 \%$ in the country [13-18].

Neural tube defect are the second most serious leading cause of neonatal mortality next to prematurity and birth 
asphyxia worldwide [19]. Moreover, NTDs are associated with substantial mortality, morbidity, disability, and psychological and economic costs $[5,20,21]$.

Studies conducted across the globe have identified different factors of NTDs. These include low socioeconomic status, maternal exposure to certain environmental factors (i.e., chemicals and pesticides), tobacco use during pregnancy, genetic factors, pregnancy in the late maternal age, poor intake of folic acid prior or during pregnancy, sex of the neonate, and no antenatal care $[2,15,20,22,23]$.

Different programs, strategies, and policies at global, regional, and national levels have been tried in the past to address the burden of congenital abnormalities at large and neural tube defects in particular. These strategies include folic acid and/or multivitamins supplementation before or during pregnancy periods $[9,10,22,24-26]$ and improvement of maternal and child health status [8, 27-30]. However, the problem related to congenital anomalies especially the NTDs have not been declined in the needed manner in developing nations including Ethiopia [11, 15, 31, 32]. Furthermore, the determinants of NTDs among newborns in Ethiopia are not well addressed in the previous studies since the studies conducted in the country were limited to the magnitude of NTDs $[16,33]$. Therefore, this study intended to investigate the determinants of NTDs among newborns.

\section{Methods}

2.1. Study Settings and Participants. The study was conducted from December 15, 2018, to January 01, 2019, among newborns in the four randomly selected public hospitals (namely, Debre Birhan, Dessie, Woldia, and Felege-Hiwot referral hospitals) those located in the Amhara Regional State, Ethiopia. The region has a total of seven referral hospitals, which serve an estimated more than 25 million populations in the region.

A hospital-based unmatched case-control study design was conducted to identify the determinants of neural tube defects (NTDs) among newborns. Neonates born after the age of viability (after 28 weeks of gestation) with a confirmed diagnosis of NTD during the study period were included as cases and those neonates born without any form NTDs during the study period were included as controls. However, pregnancies terminated before 28 weeks of gestation and neonates whose mothers were seriously ill during the study period were not included in this study.

2.2. Sample Size Determination and Sampling Techniques. To determine the sample size, various factors significantly associated with the outcome variable were considered, and the larger sample size was used for this study.

The required sample size was determined using the double population proportion formula with the assumptions of $95 \% \mathrm{CI}, 80 \%$ power, case to control ratio of $1: 2$, and $5 \%$ contingency was allowed to compensate nonresponses. Moreover, the percent of cases exposed $\left(P_{2}\right)$ and the percent of controls exposed $\left(P_{1}\right)$ were $42.9 \%$ and $27.9 \%$ respectively [23]. The sample size was calculated using Epi info version 7.0 and the final sample size became 400 (133 cases and 267).
Based on the prestudy chart review, an estimated 6,480 neonates with NTDs were born in the randomly selected four public hospitals in the previous year (from December 2017 to 30 October 2018). Then, the cases were proportionally allocated into the randomly selected public hospitals (i.e., Debre Birhan $=30$ cases, Dessie $=36$ cases, Woldia $=15$ cases, and Bahir Dar Felege - Hiwot hospital $=52$ cases $)$. The data collectors assigned to each hospital delivery ward interviewed the eligible case and the consecutive two controls until the required sample size was met.

2.3. Study Variables. The dependent variable was neural tube defects (NTDs) (present/absent). The presence of NTD cases comprises at least anyone of cases anencephaly or spinal bifida, or encephalocele based on the ICD-10 criteria [7] while the controls are neonates born without NTDs in the selected study hospitals.

Independent variables are as follows: (1) sociodemographic characteristics of the mother, (2) obstetric and medical conditions of the mother, (3) substance use during pregnancy, and (3) newborn-related factors.

2.4. Data Collection Tools and Procedures. The questionnaire used was adapted and modified from previous literature conducted in Ethiopia and other developing regions of Africa $[14,15,23,34]$. The questionnaire consisted of sociodemographic characteristics, obstetric, medical, and behavioral questions relevant to the experiences of mothers during this index pregnancy.

The data were collected using face-to-face interviews guided by structured and pretested interviewer-administered questionnaire. Besides, the maternal and neonatal medical chart review was done. The same interviewer was used to interview both cases and the consecutive two controls. The outcome variable was attributed to newborns whose medical records indicated a physician or midwife diagnosis of neonates with NTD or free of NTDs. Mothers were interviewed in private rooms to ensure their privacy and to encourage participation.

Three days of training was provided for data collectors and supervisors. Eight trained midwives or nurses who work in the labor wards of each of the selected hospitals collected the data. An independent translator translated the English language into the local language (Amharic), then back to English the measurement tool. A pretest of the questionnaire was conducted with 5\% (21 participants) of samples newborns delivered other than the selected public hospitals. The mothers of newborns were interviewed within four to six hours of delivery.

2.5. Data Processing and Analysis. The data were checked for completeness and were entered into the Epi data version 3.1. Then, the data were exported and analyzed using Stata version 14.0. The collected data were checked for normality and other assumptions. Model fitness was assessed using the Pearson or Hosmer-Lemeshow goodness-of-fit test. In addition, the correlation between the independent variables was checked.

Texts, frequency tables, graphs, mean, and standard deviations were applied to present the descriptive statistics. 
TABLE 1: Sociodemographic characteristics of participants who gave birth at public referral hospitals, Amhara Region, Ethiopia, 2019.

\begin{tabular}{|c|c|c|c|c|}
\hline Predictor variables & Category of variables & $\begin{array}{l}\text { Cases } \\
N(\%)\end{array}$ & $\begin{array}{c}\text { Controls } \\
N(\%)\end{array}$ & $X^{2}, p$ value \\
\hline \multicolumn{5}{|l|}{ Age } \\
\hline & $18-27$ & $40(31.5)$ & $96(37.8)$ & \multirow{3}{*}{$3.15, p=0.207$} \\
\hline & $28-34$ & $60(47.2)$ & $96(37.8)$ & \\
\hline & $\geq 35$ & $27(21.3)$ & $62(24.4)$ & \\
\hline \multicolumn{5}{|l|}{ Residence } \\
\hline & Rural & $75(59.1)$ & $92(36.2)$ & \multirow{2}{*}{$17.93, p=0.000$} \\
\hline & Urban & $52(40.9)$ & $162(63.8)$ & \\
\hline \multirow{4}{*}{ Education level of mother } & Illiterate & $53(41.7)$ & $29(11.4)$ & \multirow{4}{*}{$59.16, p=0.000$} \\
\hline & Primary & $23(18.1)$ & $112(44.1)$ & \\
\hline & Secondary & $32(25.2)$ & $92(36.2)$ & \\
\hline & Tertiary & $19(15.0)$ & $21(8.3)$ & \\
\hline \multicolumn{5}{|l|}{ Marital status } \\
\hline & Single & $8(6.3)$ & $13(5.1)$ & \multirow{2}{*}{$0.23, p=0.634$} \\
\hline & Married & $119(93.7)$ & $241(94.9)$ & \\
\hline \multicolumn{5}{|l|}{ Sex of the newborn } \\
\hline & Male & $38(29.9)$ & $120(47.2)$ & \multirow{2}{*}{$10.47, p=0.001$} \\
\hline & Female & $89(70.1)$ & $134(52.8)$ & \\
\hline
\end{tabular}

Binary logistic regression analysis was done to evaluate the association of NTD with each predictor variable, and variables with a $p$ value $<0.25$ were entered into the multivariable logistic regression analysis models. Multivariable logistic regression analysis was performed to identify the independent predictors of NTD using adjusted odds ratios with its corresponding 95\% confidence intervals (CI). Finally, the statistical significance level was declared at $p$ value of less than 0.05 .

\section{Results}

3.1. Sociodemographic Characteristics of Participants. In this study, a total of 127 cases and 254 controls were included with a response rate of $95.3 \%$. The mean age of the participants was 29.82 years $\pm 6.52 \mathrm{SD}$ (standard deviation).

A higher proportion of mothers in the case groups resided in rural areas compared to mothers in the control groups (59.1\% and $36.2 \%$, respectively). When comparing the highest completed educational level by mothers, a higher proportion of mothers of the cases did not attend any formal education $(41.7 \%$ compared to the mother of the controls (11.4\%) (Table 1).

3.2. Maternal Obstetric and Newborn-Related Conditions. In this study, a higher proportion of mothers of cases had no antenatal care follow-up (15.5\%) compared to mothers of controls (5.5\%). Moreover, a higher percent of mothers with cases were not supplemented with folic acid (77.9\%) compared to mothers of controls (49.2\%). Furthermore, mothers with cases had twice-higher exposure history of previous NTDs compared to mothers with controls $(62.2 \%$ and $28.38 \%$, respectively). Finally, a higher proportion of mothers of cases used sub- stances (drugs, alcohol, khat, and cigarette) during pregnancy (29.1\%) compared to the mothers of controls (9.1\%) (Table 2).

3.3. Types of Neural Tube Defects. In this study, the commonest type of neural tube defects among newborns is anencephaly, which accounts for $48.1 \%$ of total cases. The second and the third common types of NTDs are spinal bifida and encephalon that account for $36.2 \%$ and $11.8 \%$ of total cases, respectively. Besides, the rest $3.9 \%$ of cases were other forms of NTDs (craniorachischisis and lipomas) (Figure 1).

3.4. Determinants of Neural Tube Defects. The predictor variables with a $p$ value of less than 0.25 in the bivariate logistic regression analysis were entered into the multivariable logistic regression analysis model to control the influence of potential confounding variables. The correlation between the independent variables was checked. Moreover, the fitness of the model was also assessed.

After controlling the covariates; women who resided in rural areas had $78 \%$ higher odds of newborns with neural tube defects (NTDs) compared to women who resided in urban residence $(\mathrm{AOR}=1.78: 95 \% \mathrm{CI} 1.02,3.11)$. The likelihood of NTDs was $81 \%$ higher among newborns who had illiterate mothers compared to those who had mothers attended tertiary education levels $(\mathrm{AOR}=1.81$ : 95\% CI $1.07,4.61)$. Female newborns had twice-higher odds of NTDs compared to male neonates (AOR $=1.95: 95 \%$ CI 1.09, 3.50). Women who had no antenatal care visits had twice-greater odds of newborns with NTDs compared to those who had antenatal care visits $(\mathrm{AOR}=1.93: 95 \% \mathrm{CI} 1.17,5.04)$. The odds of NTDs were less by $63 \%$ among newborns whose mothers had taken folic acid before or during pregnancy 
TABLe 2: The maternal obstetric, behavioral, and newborn-related conditions, Amhara Region, Ethiopia, 2019.

\begin{tabular}{|c|c|c|c|c|}
\hline Predictor variables & Category of variables & $\begin{array}{l}\text { Cases } \\
N(\%)\end{array}$ & $\begin{array}{l}\text { Controls } \\
N(\%)\end{array}$ & $X^{2}, p$ value \\
\hline \multicolumn{5}{|l|}{ Parity } \\
\hline & Multipara & $82(64.6)$ & $163(64.2)$ & \multirow{2}{*}{$0.015, p=0.940$} \\
\hline & Primipara & $45(35.4)$ & $91(35.8)$ & \\
\hline \multirow[t]{2}{*}{ ANC follow-up for this index pregnancy } & Yes & $108(85.0)$ & $240(94.5)$ & \multirow{2}{*}{$9.56, p=0.002$} \\
\hline & No & $19(15.0)$ & $14(5.5)$ & \\
\hline \multicolumn{5}{|l|}{ Gestational age at birth } \\
\hline & $<37$ weeks & $11(8.7)$ & $21(8.3)$ & \multirow{2}{*}{$0.017, p=0.896$} \\
\hline & $\geq 37$ weeks & $116(91.3)$ & $233(91.7)$ & \\
\hline \multirow{2}{*}{$\begin{array}{l}\text { Folic acid supplemented prior to } \\
\text { or during pregnancy }\end{array}$} & No & $99(77.9)$ & $125(49.2)$ & \multirow{2}{*}{ 28.87, $p=0.000$} \\
\hline & Yes & $28(22.1)$ & $129(50.8)$ & \\
\hline \multicolumn{5}{|l|}{ Planned pregnancy } \\
\hline & Yes & $51(40.2)$ & $93(36.6)$ & \multirow{2}{*}{$0.45, p=0.501$} \\
\hline & No & $76(59.8)$ & $161(63.4)$ & \\
\hline \multicolumn{5}{|l|}{ Previous history of NTDs } \\
\hline & No & $48(37.8)$ & $182(71.7)$ & \multirow{2}{*}{$40.57, p=0.000$} \\
\hline & Yes & $79(62.2)$ & $72(28.3)$ & \\
\hline \multirow{2}{*}{$\begin{array}{l}\text { Medical problems during this pregnancy } \\
\text { (PROM, DM, HTN, HIV, UTI, etc.) }\end{array}$} & Yes & $18(14.2)$ & $19(7.5)$ & \multirow{2}{*}{$4.33, p=0.038$} \\
\hline & No & $109(85.8)$ & $235(92.5)$ & \\
\hline \multirow{2}{*}{$\begin{array}{l}\text { Previous adverse birth outcomes } \\
\text { (stillbirth, PTB, LBW, abortion, and SGA) }\end{array}$} & Yes & $25(19.7)$ & $32(12.6)$ & \multirow{2}{*}{$3.34, p=0.068$} \\
\hline & No & $102(80.3)$ & $222(87.4)$ & \\
\hline \multirow{2}{*}{$\begin{array}{l}\text { Substance use during pregnancy } \\
\text { (drugs, alcohol, khat, and cigarette) }\end{array}$} & Yes & $27(29.1)$ & $23(9.1)$ & \multirow{2}{*}{$25.73, p=0.000$} \\
\hline & No & $90(70.9)$ & $231(90.9)$ & \\
\hline \multicolumn{5}{|l|}{ Onset of labor } \\
\hline & Spontaneous & $115(90.6)$ & $238(93.7)$ & \multirow{2}{*}{$1.23, p=0.267$} \\
\hline & Induced & $12(9.4)$ & $16(6.3)$ & \\
\hline \multicolumn{5}{|l|}{ Mode of delivery } \\
\hline & SVD & $105(82.7)$ & $224(88.2)$ & \multirow{3}{*}{$2.23, p=0.527$} \\
\hline & C-section & $14(11.0)$ & $19(7.5)$ & \\
\hline & Instrumental assisted delivery & $8(6.3)$ & $11(4.3)$ & \\
\hline \multicolumn{5}{|l|}{ Weight of the newborn } \\
\hline & $<2500$ & $87(68.5)$ & $9(3.5)$ & \multirow{2}{*}{$189.56, p=0.000$} \\
\hline & $\geq 2500$ & $40(31.5)$ & $245(96.5)$ & \\
\hline
\end{tabular}

Key: DM, diabetes mellitus; HTN, hypertension; HIV, human immune virus; UTI, urinary tract infection; PROM, premature rupture of membrane; PTB, preterm birth; LBW, low birth weight; SGA, small for gestational age; ANC, antenatal care; NTD, neural tube defects.

compared to those women who were not supplemented with folic acids (AOR = 0.37: 95\% CI 021, 0.65). Women who had a previous history of NTDs had 4-folds higher odds of newborns with NTDs compared to their counterparts (AOR $=4.39:$ 95\% CI 2.42, 7.96). The likelihood of NTDs was 58\% lesser among neonates whose mothers never used any substance during pregnancy compared to those who were taking substance (drugs, alcohol, khat, and cigarette) $(\mathrm{AOR}=0.42: 95 \%$ CI $0.21,0.88)$. Moreover, women who had experienced medical illnesses during pregnancy had $73 \%$ lesser odds of neonates with NTDs compared to that experienced medical illness during pregnancy $(\mathrm{AOR}=0.27$ : 95\% CI 0.11, 0.69). Finally, being a female neonate was the independent predictor of NTD compared to male neonates 


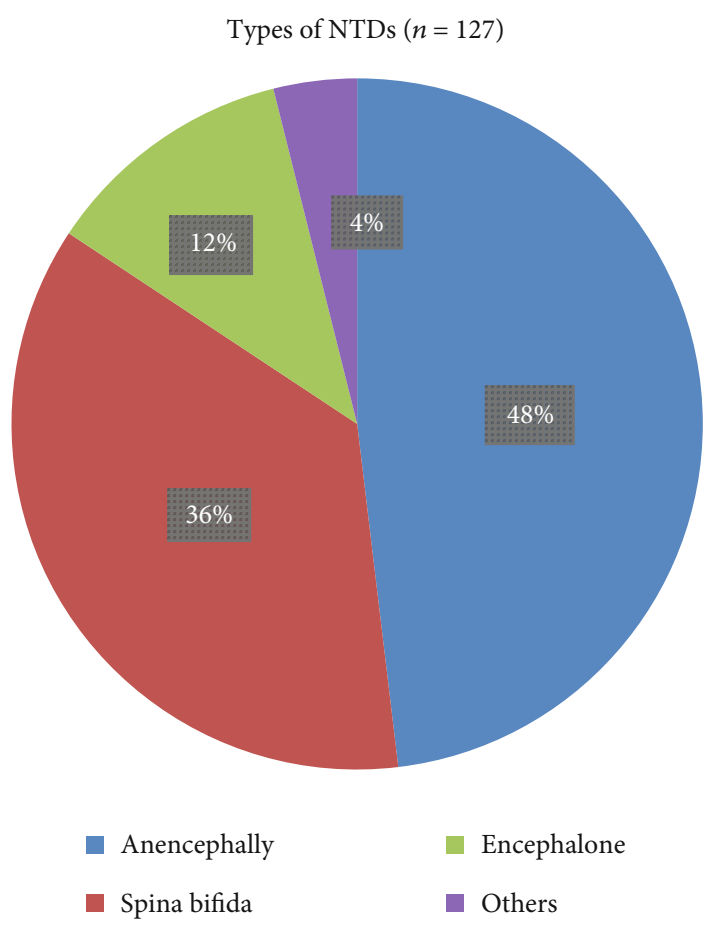

Figure 1: Types of NTDs among the cases of the neonates born in the hospitals, Amhara Region, Ethiopia, 2019.

$(\mathrm{AOR}=1.95: 95 \%$ CI 1.09, 3.50). However, having planned pregnancy, maternal age, having a history of adverse birth outcomes (i.e., abortion, PTB, LBW, and stillbirth) before this index pregnancy, and mode of delivery were not associated with neonatal NTDs in this study (Table 3).

\section{Discussion}

Defects of the neural tube involve the imperfect development of the neuropore during embryogenesis and the subsequent maldevelopment of the adjacent bone and mesenchymal structures [35]. In our study, nearly fifty percent (48\%) of the NTD cases were contributed by anencephaly. This finding is similar to studies conducted in Addis Ababa Teaching Hospitals, Ethiopia (54.1\%) [15], Tigray, Northern Ethiopia (66.4 per 10,000 NTD cases) [17], Gujarat hospital, India (26\%) [31], and Southwest Iran (86.8\%) [36]. This could be justified by the fact that anencephaly is the most common NTDs, and it developed before any of the central nervous system anomalies, developed within 1 month of conception [37]. Thus, this might be the reason for its dominancy in the current study and previous studies conducted across the world.

Studies indicated that supplementation of folic acid three months before or during pregnancy can decrease NTDs by $50-70 \%[24,38,39]$. Our study revealed women who had taken folic acid before or during pregnancy had $63 \%$ less risk of births with NTDs compared to those who were not supplemented with folic acids. This finding is similar to studies conducted in Addis Ababa Teaching Hospitals, Ethiopia [15], Tigray, Northern Ethiopia [17], and Northwest Ethiopia [18]. Moreover, the result is consistent with studies conducted in Hungary [40], Adama hospital, Ethiopia [41],
Jordan [42], Saudi Arabia [43], and Kingdom of Saudi Arabia [44]. Thus, in developing nations where the practice of preconception folic acid supplementation is negligible [16], folic acid fortification and supplementation policies and programs are mandatory to reduce the burden on NTDs [45-47].

In this study, women who had a previous history of NTDs had 4-folds higher odds of newborns with NTDs compared to their counterparts. This finding is very consistent with a study done in Addis Ababa City Administrative and Amhara Region, Ethiopia [14], a study conducted in central Iran [48], and a study conducted in western Iranian obstetrical centers [49]. Thus, folic acid supplementation has been shown to reduce the incidence and recurrence of NTDs [37, 39], and women with previous exposure to NTDs problem are recommended to take the maximum (4 to $5 \mathrm{mg}$ ) dose of folic acid on a daily basis $[26,50]$.

Previous studies recommended women to avoid harmful substances (i.e., tobacco, illicit drugs, and alcohol) during their pregnancy period $[3,51]$. Similarly, the current study suggested that the likelihood of NTDs was 58\% lesser among neonates whose mothers never used any substance during pregnancy compared to those who were taking substance (alcohol, khat, illicit drugs, and cigarette). This finding is consistent with a study done in North America [52], and a study conducted in western Iranian obstetrical centers [49].

In this study, women who resided in rural areas had 78\% higher odds of newborns with neural tube defects (NTDs) compared to women who resided in urban residences. This is similar to a study conducted in Tigray regional state of Ethiopia [23]. Women who resided in rural areas that are inaccessible to the available health services might explain this. Thus, they are unable to get counseling and supplementation with folic acid that prevent the occurrence of NTDs. 
TABLe 3: Determinants of NTDs among neonates born at public hospitals, Amhara Region, Ethiopia, 2019.

\begin{tabular}{|c|c|c|c|c|c|}
\hline \multirow{2}{*}{ Predictor variables } & & \multicolumn{2}{|c|}{ Birth outcomes } & \multirow{2}{*}{ COR $(95 \% \mathrm{CI})$} & \multirow{2}{*}{$\operatorname{AOR}(95 \% \mathrm{CI})$} \\
\hline & & Cases & Controls & & \\
\hline \multirow{2}{*}{ Residence } & Rural & $75(59.1)$ & $92(36.2)$ & $2.54(1.64,3.93)$ & $1.78(1.02,3.11) *$ \\
\hline & Urban & $52(40.9)$ & $162(63.8)$ & 1.00 & 1.00 \\
\hline \multirow{3}{*}{ Mothers' age (in completed years) } & $18-27$ & $40(31.5)$ & $96(37.8)$ & 1.00 & 1.00 \\
\hline & $28-34$ & $60(47.2)$ & $96(37.8)$ & $1.50(0.92,2.44)$ & $1.74(0.92,3.30)$ \\
\hline & $\geq 35$ & $27(21.3)$ & $62(24.4)$ & $1.04(0.58,1.87)$ & $0.78(0.36,1.69)$ \\
\hline \multirow{4}{*}{ Mothers' completed educational level } & Illiterate & $53(41.7)$ & $29(11.4)$ & $2.02(0.93,4.53)$ & $1.81(1.07,4.61) *$ \\
\hline & Primary & $23(18.1)$ & $112(44.1)$ & $0.23(0.11,0.48)$ & $0.13(0.05,0.35)$ \\
\hline & Secondary & $32(25.2)$ & $92(36.2)$ & $0.38(0.18,0.81)$ & $0.30(0.12,0.75)$ \\
\hline & Tertiary & $19(15.0)$ & $21(8.3)$ & 1.00 & 1.00 \\
\hline \multirow{2}{*}{ Sex of the newborn } & Male & $38(29.9)$ & $120(47.2)$ & 1.00 & 1.00 \\
\hline & Female & $89(70.1)$ & $134(52.8)$ & $2.09(1.34,3.29)$ & $1.95(1.09,3.50) *$ \\
\hline \multirow{2}{*}{ ANC follow-up } & Yes & $108(85.0)$ & $240(94.5)$ & 1.00 & 1.00 \\
\hline & No & $19(15.0)$ & $14(5.5)$ & $3.02(1.46,6.23)$ & $1.93(1.17,5.04) *$ \\
\hline \multirow{2}{*}{ Folic acid supplemented prior to or during pregnancy } & No & $99(77.9)$ & $125(49.2)$ & 1.00 & 1.00 \\
\hline & Yes & $28(22.1)$ & $129(50.8)$ & $0.27(0.17,0.44)$ & $0.37(0.21,0.65) *$ \\
\hline \multirow{2}{*}{ Pregnancy was planned } & Yes & $51(40.2)$ & $93(36.6)$ & 1.00 & 1.00 \\
\hline & No & $76(59.8)$ & $161(63.4)$ & $0.86(0.55,1.33)$ & $0.94(0.54,1.66)$ \\
\hline \multirow{2}{*}{ Previous history of NTD(s) } & No & $48(37.8)$ & $182(71.7)$ & 1.00 & 1.00 \\
\hline & Yes & $79(62.2)$ & $72(28.3)$ & $4.16(2.65,6.53)$ & $4.39(2.42,7.96) *$ \\
\hline \multirow{2}{*}{$\begin{array}{l}\text { Substance use during pregnancy } \\
\text { (alcohol, khat, cigarette, and drugs) }\end{array}$} & Yes & $27(29.1)$ & $23(9.1)$ & 1.00 & 1.00 \\
\hline & No & $90(70.9)$ & $231(90.9)$ & $0.24(0.14,0.43)$ & $0.42(0.21,0.88) *$ \\
\hline \multirow{2}{*}{$\begin{array}{l}\text { Previous adverse birth outcomes } \\
\text { (stillbirth, PTB, LBW, abortion, and SGA) }\end{array}$} & Yes & $25(19.7)$ & $32(12.6)$ & 1.00 & 1.00 \\
\hline & No & $102(80.3)$ & $222(87.4)$ & $0.59(0.33,1.05)$ & $0.61(0.28,1.29)$ \\
\hline \multirow{2}{*}{$\begin{array}{l}\text { Medical problems during this pregnancy } \\
\text { (PROM, DM, HTN, HIV, UTI, etc.) }\end{array}$} & Yes & $18(14.2)$ & $19(7.5)$ & 1.00 & 1.00 \\
\hline & No & $109(85.8)$ & $235(92.5)$ & $0.49(0.25,0.96)$ & $0.27(0.11,0.69) *$ \\
\hline \multirow{3}{*}{ Mode of delivery } & SVD & $105(82.7)$ & $224(88.2)$ & 1.00 & 1.00 \\
\hline & C-section & $14(11.0)$ & $19(7.5)$ & $1.57(0.76,3.25)$ & $2.23(0.84,5.91)$ \\
\hline & Instrumental delivery & $8(6.3)$ & $11(4.3)$ & $1.55(0.61,3.97)$ & $2.05(0.63,6.59)$ \\
\hline
\end{tabular}

Key: AOR, adjusted odds ratio; COR, crude odds ratio; CI, confidence interval; $* p<0.05$. DM, Diabetes Mellitus; HTN, Hypertension; HIV, Human Immune Virus; UTI, Urinary Tract Infection; PROM, Premature Rupture of Membrane; PTB, Preterm Birth; LBW, Low Birth Weight; SGA, Small for Gestational Age; ANC, Antenatal Care; NTDs, Neural Tube Defects.

Studies revealed that women with no education gave birth with NTDs compared to literate women [53]. Similarly, in the current study, the likelihood of NTDs was $81 \%$ higher among newborns who had illiterate mothers compared to those who had mothers who attended tertiary education levels. In the rural part of Ethiopia, most the women have not attended formal education, and they are not aware of the available health services in the existing health facilities. Consequently, illiterate women are more prone to have birth with NTDs than those who have attended some forms of education.

Women who had no antenatal care visits had twice-greater odds of newborns with NTDs compared to those who had antenatal care visits. This finding is similar to a study done in Northwest Ethiopia [18], and a study conducted in western
Iranian obstetrical centers [49]. Women who have no ANC visits during pregnancy will not have information when to take folic acid supplementation. Thus, these women are more prone to develop many complications related to pregnancy, birth, and postpartum causes, and they will end up their pregnancy with bad outcome including NTDs compared to those have ANC follow-ups.

Women who had experienced medical illnesses during pregnancy had 73\% lesser odds of neonates with NTDs compared to that experienced medical illness during pregnancy. This finding is in line with a study conducted in Northwest Ethiopia [18]. Therefore, women with any medical problems during their pregnancy and over-the-counters need to be given attention to avert the burden on congenital anomalies [3]. Thus, 
women with medical illness before or during pregnancy may have a low intake of foods enriched with folic acid that prone them to have birth with NTDs.

In this study, being female neonates was 2-folds a greater risk of NTD compared to male neonates. This is similar to studies conducted in Addis Ababa Teaching Hospitals, Ethiopia [15], Tigray regional state of Ethiopia [23], Batna Region, Algeria [54], Colorado, United States [53], Saudi Arabia [43], and five states of Northern China [55]. The mechanism on how the occurrence of NTDs varies between sexes is not well understood $[21,39]$. Thus, there is no single justification why neural tube defect affects more females compared to males.

4.1. Limitations of the Study. First, the study deals with personal and sensitive behaviors, such as substance use during pregnancy. Thus, this might introduce social desirability bias. Second, the study was facility-based, in which institutional delivery is very low, and this study may not represent as close to $74 \%$ of deliveries which take place at home in the region. Lastly, the study did not address the genetic, syndromic, and chromosomal causes of NTD that are not preventable by folic acid.

\section{Conclusion}

The study identified different factors associated with NTDs among newborns in the region. After controlling the effect of covariates, residence, maternal education level, sex of the newborn, antenatal care follow-ups, previous history of birth with NTDs, folic acid intake, substance use during pregnancy, and medical illnesses during pregnancy were the independent predictors of NTDs among neonates. Therefore, comprehensive preventive strategies focused on identified risk factors are needed at regional and national government levels. Further research to address the genetic factors of NTDs is recommended.

\section{Abbreviations}

ANC: Antenatal care

EDHS: Ethiopian Demographic and Health Survey

GA: Gestational age

NICU: Neonatal intensive care unit

NTDs: Neural tube defects

WHO: World Health Organization.

\section{Data Availability}

All materials and data related to this article are included in the main document of the manuscript. However, if anyone has interested to have raw data, he/she can contact the corresponding author.

\section{Ethical Approval}

Ethical approval was obtained from the Dream Science and Technology Institutional Health Research Ethics Review Committee with the approval letter of DSTC/DHS/031/2019. Then, a permission letter was written for selected public hospitals for cooperation and support. We avoided personal identification to ensure confidentiality and anonymity of study participants.

\section{Conflicts of Interest}

The authors declare that they have no competing interests.

\section{References}

[1] WHO, Birth defects: Sixty-Third World Health Assembly Provisional agenda item 11.7, World Health Organization, Geneva, 2010.

[2] WHO, “Congenital anomalies," 2016, February 2020, https:// www.who.int/en/news-room/fact-sheets/detail/congenitalanomalies.

[3] CDC, Updated Estimates of Neural Tube Defects Prevented by Mandatory Folic Acid Fortification, U.S. Department of Health and Human Services, Centers for Disease Control and Prevention, USA, 2015.

[4] WHO, International statistical classification of diseases and related health problems (ICDs-10), World Health Organization, 20 Avenue Appia, 1211 Geneva 27, Switzerland, 2016, 10th revision.

[5] March of Dimes, WHO, Global report on birth defects the hidden toll of dying and disabled children, March of Dimes Birth Defects Foundation, New York, 2006.

[6] WHO/CDC/ICBDSR, Birth defects surveillance: a manual for programme managers, World Health Organization, Geneva, 2014.

[7] WHO, International Statistical Classification of Diseases and Related Health Problems (ICD-10), World Health Organization, 20 Avenue Appia, 1211 Geneva 27, Switzerland, 2011.

[8] A. Flores, D. Valencia, A. Sekkarie et al., "Building capacity for birth defects surveillance in Africa: Implementation of an intermediate birth defects surveillance workshop," Journal of Global Health Perspectives, vol. 11, no. 1, 2015.

[9] D. Taruscio, Folic Acid: From Research to Public Health Practice, Istituto Superiore di Sanità, 2004.

[10] J. Williams, C. T. Mai, J. Mulinare et al., "Updated estimates of neural tube defects prevented by mandatory folic acid fortification-United States, 1995-2011," MMWR Morbidity and Mortality Weekly Report, vol. 64, no. 1, p. 1, 2015.

[11] J. K. Morris, A. L. Springett, R. Greenlees et al., "Trends in congenital anomalies in Europe from 1980 to 2012," PLoS One, vol. 13, no. 4, article e0194986, 2018.

[12] I. Zaganjor, A. Sekkarie, B. L. Tsang et al., "Describing the prevalence of neural tube defects worldwide: a systematic literature review," PLoS One, vol. 11, no. 4, 2016.

[13] M. Taye, M. Afework, W. Fantaye, E. Diro, and A. Worku, "Magnitude of birth defects in central and Northwest Ethiopia from 2010-2014: a descriptive retrospective study," PLoS One, vol. 11, no. 10, article e0161998, 2016.

[14] M. Taye, M. Afework, W. Fantaye, E. Diro, and A. Worku, "Congenital anomalies prevalence in Addis Ababa and the Amhara region, Ethiopia: a descriptive cross-sectional study," BMC Pediatrics, vol. 19, no. 1, p. 234, 2019.

[15] A. Gedefaw, S. Teklu, and B. T. Tadesse, "Magnitude of neural tube defects and associated risk factors at three teaching hospitals in Addis Ababa, Ethiopia," BioMed Research International, vol. 2018, Article ID 4829023, 10 pages, 2018. 
[16] G. Sorri and E. Mesfin, "Patterns of neural tube defects at two teaching hospitals in Addis Ababa, Ethiopia a three years retrospective study," Ethiopian Medical Journal, vol. 53, no. 3, pp. 119-126, 2015.

[17] B. A. Berihu, A. L. Welderufael, Y. Berhe et al., "High burden of neural tube defects in Tigray, Northern Ethiopia: Hospital-based study," PLoS One, vol. 13, no. 11, article e0206212, 2018.

[18] D. Atlaw, A. Worku, M. Taye, D. Woldeyehonis, and A. Muche, "Neural tube defect and associated factors in Bale Zone Hospitals, Southeast Ethiopia," Journal of Pregnancy and Child Health, vol. 6, article 1000412, p. 412, 2019.

[19] WHO, "MCEE-WHO methods and data sources for child causes of death 2000-2016," Department of Evidence, Information and Research (WHO, Geneva) and Maternal Child Epidemiology Estimation (MCEE), 2018, December 2019, https:// www.who.int/healthinfo/global_burden_disease/en/.

[20] A. Behrooz and M. H. Gorjizadeh, "Prevalence and correlates of neural tube defect in south West Iran: retrospective analysis," Sultan Qaboos University Medical Journal, vol. 7, no. 1, pp. 31-34, 2007.

[21] N. D. E. Greene and A. J. Copp, "Neural tube defects," Annual Review of Neuroscience, vol. 37, no. 1, pp. 221-242, 2014.

[22] N. Øyen, S. F. Olsen, S. Basit et al., "Association between maternal folic acid supplementation and congenital heart defects in offspring in birth cohorts from Denmark and Norway," Journal of the American Heart Association, vol. 8, no. 6, article e011615, 2019.

[23] B. A. Berihu, A. L. Welderufael, Y. Berhe et al., "Maternal risk factors associated with neural tube defects in Tigray regional state of Ethiopia," Brain \& Development, vol. 41, no. 1, pp. 11-18, 2019.

[24] WHO, Guideline: optimal serum and red blood cell folate concentrations in women of reproductive age for prevention of neural tube defects, Department of Nutrition for Health and Development, World Health Organization, 2015.

[25] S. R. Walani and J. Biermann, "March of Dimes Foundation: leading the way to birth defects prevention," Public Health Reviews, vol. 38, no. 1, p. 12, 2017.

[26] WHO, Prevention of neural tube defects: integrated management of pregnancy and childbirth (IMPAC), World Health Organization, 2006.

[27] FMOH [Ethiopia], Health Sector Transformation Plan (HSTP 2016-2020), Federal Minstry of Health, Addis Ababa, Ethiopia, 2015.

[28] FMOH [Ethiopia], JSI, “Addressing Community Maternal and Neonatal Health in Ethiopia," Report from National Scoping Exercise and National Workshop to Increase Demand, Accesses and Use of Community Maternal and Neonatal Health Services, Federal Minstry of Health (FMOH), Addis Ababa, Ethiopia, 2009.

[29] FMOH [Ethiopia], National Newborn and Child Survival Strategy Document Brief Summary 2015/16-2019/20, Federal Minstry of Health, Addis Ababa, Ethiopia, 2015.

[30] United Nations, "Transforming our world: the 2030 Agenda for sustainable development," 2015, http://wwwunorg/ sustainabledevelopment/health/.

[31] V. M. Sharma, B. B. Airao, R. A. Zala, and M. R. Pandya, "Pattern of various congenital anomalies: a hospital based study," Indian Journal of Obstetrics and Gynecology Research, vol. 5, no. 4, pp. 549-552, 2018.
[32] A. K. Njamnshi, V. de Djientcheu, A. Lekoubou et al., "Neural tube defects are rare among black Americans but not in subSaharan black Africans: the case of Yaounde - Cameroon," Journal of the Neurological Sciences, vol. 270, no. 1-2, pp. 1317, 2008.

[33] Central Statistical Agency [Ethiopia], ICF, International, Ethiopia Demographic and Health Survey 2011, Central Statistical Agency and ICF International, Addis Ababa, Ethiopia and Calverton, Maryland, USA, 2012.

[34] D. Mumpe-Mwanja, L. Barlow-Mosha, D. Williamson et al., "A hospital-based birth defects surveillance system in Kampala, Uganda," BMC Pregnancy Childbirth, vol. 19, no. 1, p. 372, 2019.

[35] B. A. Kaufman, "Neural tube defects," Pediatric Clinics, vol. 51, no. 2, pp. 389-419, 2004.

[36] S. Ebrahimi, S. Ashkani-Esfahani, and F. Bagheri, "Prevalence of neural tube defects in Yasuj, South West Iran," Shiraz E Medical Journal, vol. 14, no. 1, 2013.

[37] H. V. Toriello and for the Professional P, Guidelines C, "Folic acid and neural tube defects," Genetics in Medicine, vol. 7, no. 4, pp. 283-284, 2005.

[38] M. A. Salih, W. R. Murshid, and M. Z. Seidahmed, "Epidemiology, prenatal management, and prevention of neural tube defects," Saudi Medical Journal, vol. 35, Supplement 1, pp. S15-S28, 2014.

[39] March of Dimes, "Neural tube defects: key facts," 2018, February 2020, https://www.marchofdimes.org/complications/ neural-tubedefects.aspx.

[40] A. E. Czeizel, Z. Bártfai, and F. Bánhidy, "Primary prevention of neural-tube defects and some other congenital abnormalities by folic acid and multivitamins: history, missed opportunity and tasks," Therapeutic Advances in Drug Safety, vol. 2, no. 4, pp. 173-188, 2011.

[41] M. A. Dessie, E. G. Zeleke, S. B. Workie, and A. W. Berihun, "Folic acid usage and associated factors in the prevention of neural tube defects among pregnant women in Ethiopia: cross-sectional study," BMC Pregnancy and Childbirth, vol. 17, no. 1, p. 313, 2017.

[42] H. E. Aqrabawi, "Incidence of neural tube defects among neonates at King Hussein Medical Centre, Jordan," Eastern Mediterranean Health Journal, vol. 11, no. 4, 2005.

[43] A. M. Kurdi and M. A. Majeed-Saidan, "World Birth Defects Day. Towards a national registry for birth defects in Saudi Arabia," Saudi Medical Journal, vol. 36, no. 2, pp. 143-145, 2015.

[44] M. Z. Seidahmed, O. B. Abdelbasit, M. M. Shaheed et al., "Epidemiology of neural tube defects," Saudi Medical Journal, vol. 35, Supplement 1, pp. S29-S35, 2014.

[45] A. L. Flores, C. Vellozzi, D. Valencia, and J. Sniezek, "Global burden of neural tube defects, risk factors, and prevention," Indian Journal of Community Health, vol. 26, Supplement 1, pp. 3-5, 2014.

[46] M. A. Alsammani, A. Kunna, and E. M. Adam, "Factors associated with folic acid knowledge and intake among pregnant women in Sudan," Eastern Mediterranean Health Journal, vol. 23, no. 10, pp. 662-669, 2017.

[47] M.-K. Thong, "Birth defects registries in the genomics era: challenges and opportunities for developing countries," Frontiers in Pediatrics, vol. 2, pp. 60-60, 2014.

[48] A. Talebian, B. Soltani, M. Sehat, A. Zahedi, and A. M. T. Noorian, "Incidence and risk factors of neural tube defects in 
Kashan, Central Iran," Iranian Journal of Child Neurology, vol. 9, no. 3, pp. 50-56, 2015.

[49] F. Zaheri, F. Ranaie, R. Shahoei, L. Hasheminasab, and D. Roshani, "Risk factors associated with neural tube defects in infants referred to western Iranian obstetrical centers; 2013-2014," Electronic Physician, vol. 9, no. 6, pp. 46364642, 2017.

[50] M. Ryan-Harshman and W. Aldoori, "Folic acid and prevention of neural tube defects," Canadian Family Physician, vol. 54, no. 1, pp. 36-38, 2008.

[51] M. Anderson and I. Choonara, "Drug misuse during pregnancy and fetal toxicity," Archives of disease in childhood Fetal and neonatal edition, vol. 92, no. 5, pp. F332-F333, 2007.

[52] C. M. Benedum, M. M. Yazdy, A. A. Mitchell, and M. M. Werler, "Risk of spina bifida and maternal cigarette, alcohol, and coffee use during the first month of pregnancy," International Journal of Environmental Research and Public Health, vol. 10, no. 8, pp. 3263-3281, 2013.

[53] T. F. Farley, S. J. Hambidge, and M. F. Daley, "Association of low maternal education with neural tube defects in Colorado, 1989-1998," Public Health, vol. 116, no. 2, pp. 89-94, 2002.

[54] R. Bourouba, B. Houcher, and N. Akar, "Risk factors of neural tube defects: a reality of Batna region in Algeria," Egyptian Journal of Medical Human Genetics, vol. 19, no. 3, pp. 225229, 2018.

[55] J. Liu, J. Xie, Z. Li, N. D. E. Greene, and A. Ren, "Sex differences in the prevalence of neural tube defects and preventive effects of folic acid (FA) supplementation among five counties in northern China: results from a population-based birth defect surveillance programme," BMJ Open, vol. 8, no. 11, article e022565, 2018. 